\title{
Perbedaan Hasil Belajar Biologi Menggunakan Model Jigsaw II dan Think Pair Share (TPS) Kelas X IPA Pada Materi Ekosistem di SMA Negeri 18 Batam
}

\section{Differences in Biology Learning Outcomes Using Jigsaw II and Think Pair Share (TPS) Model on the Subject of Ecosystem at Class X Natural Sciences SMA Negeri 18 Batam}

\author{
Alnita Saputri, Fauziah Syamsi*, Notowinarto \\ Program Studi Pendidikan Biologi Fakultas Keguruan dan Ilmu Pendidikan, Universitas Riau \\ Kepulauan.*Correspondent email: fauziahsyamsi@gmail.com
}

Received: 11 June 2020 | Accepted: 09 July 2020 | Published: 20 July 2020

\begin{abstract}
Abstrak. Pada proses pembelajaran, guru diharapkan dapat menggunakan model pembelajaran yang tepat demi ketercapaian hasil belajar dan peningkatan mutu pembelajaran. Penggunaan model pembelajaran yang tepat akan memberikan dampak yang baik terhadap siswa. Penelitian ini bertujuan untuk mengetahui perbedaan hasil belajar antara model Jigsaw II dan Think Pair Share (TPS) pada pokok bahasan Ekosistem kelas X IPA SMAN 18 Batam Tahun Ajaran 2018/2019. Jenis penelitian adalah quasi eksperimental, dengan populasi terjangkau semua siswa kelas X IPA yang terdiri dari 3 kelas. Dalam penelitian ini sebagai sampel terpilih adalah kelas X IPA 2 sebagai kelas Jigsaw II (ekperimen 1) dan kelas X IPA 1 sebagai kelas TPS (eksperimen 2). Uji prasyarat analisis mempelihatkan distribusi data normal $\left(\mathrm{X}^{2}\right.$ hitung $<\mathrm{X}^{2}$ tabel5\%) dan homogen (Fhit $<$ Ftab5\%) pada kedua kelas eksperimen. Analisis data menggunakan Uji t $(\alpha=5 \%)$. Hasil penelitian menunjukan bahwa ratarata nilai hasil belajar kelas Jigsaw II adalah 82,5 dan kelas TPS adalah 76,5. Uji t menunjukan nilai $\mathrm{t}_{\text {hitung }}=2,26>\mathrm{t}_{\text {tabel }}=1,99$ maka $\mathrm{H}_{0}$ ditolak dan $\mathrm{H}_{\mathrm{a}}$ diterima. Terdapat perbedaan yang signifikan antara hasil belajar siswa menggunakan Jigsaw II dan TPS kelas X IPA materi Ekosistem SMA Negeri 18 Batam. Penerapan model pembelajaran yang tepat pada materi tertentu dapat meningkatkan hasil belajar siswa.
\end{abstract}

Kata Kunci: Model Pembelajaran, Jigsaw II, Think Pair Share (TPS), Hasil Belajar Biologi.

\begin{abstract}
In the learning process, teachers are expected to use appropriate learning models to achieve learning outcomes and improve the quality of learning. The use of appropriate learning models will have a good impact on students. This study aims to determine the differences in learning outcomes between the Jigsaw II and Think Pair Share (TPS) models on the subject of Ecosystem Class X Science SMAN 18 Batam in Academic Year 2018/2019. This type of research is quasy-experiment design, with an affordable population of all class X students of Natural Sciences consisting of 3 classes. In this study the selected sample is Class X Natural Science 2 as a Jigsaw II class (Experiment 1) and Class X Natural Science 1 as TPS Class (experiment 2). The analysis prerequisite test shows the distribution of normal data $\left(X^{2}\right.$ value $<X^{2}$ tab $\left.5 \%\right)$ and homogeneous (Fhit $<$ Ftable $\left.5 \%\right)$ in both experimental classes. Data analysis using $t$ test $(\alpha=5 \%)$. The results showed the average value of Jigsaw II class learning outcomes was 82.5 and the TPS class was 76.5. The t test showed the value of Tvalue $=2.26>$ Ttab5\% $=$ 1,99 then $\mathrm{Ho}$ is rejected and $\mathrm{Ha}$ is accepted. The conclusion there is significant between student learning outcomes using Jigsaw II and TPS class X IPA material Ecosystem High School 18 Batam. Applying the right learning model to certain material can improve student learning outcomes.
\end{abstract}

Keywords: Learning Model,, Jigsaw II, Think Pair Share (TPS),Biology learning outcomes

\section{PENDAHULUAN}

Pendidikan merupakan usaha untuk mengembangkan dan membina potensi sumber daya manusia melalui berbagai kegiatan belajar mengajar yang diselenggarakan pada semua jenjang pendidikan baik ditingkat dasar, menengah, maupun perguruan tinggi (Samaela, et al., 2017). Berbagai mata pelajaran yang ada di dalam dunia pendidikan, salah satunya yaitu mata pelajaran biologi. Pelajaran biologi adalah salah satu mata pelajaran yang sangat penting dan sangat dekat 
dengan masalah kehidupan sehari-hari namun kadang sulit dipahami oleh siswa. Oleh karena itu, guru harus dapat memunculkan daya pikat terhadap siswa dengan cara menggunakan model pembelajaran yang tepat demi ketercapaian hasil belajar dan peningkatan mutu pembelajaran. Menurut Slameto (2010) dan Rinaldi (2018) penggunaan model pembelajaran yang sesuai dengan karakteristik materi akan memotivasi dan menarik perhatian siswa sehingga diperoleh hasil belajar yang sesuai dengan yang diharapkan.

Berdasarkan hasil observasi yang dilakukan di SMA Negeri 18 Batam diketahui bahwa pembelajaran biologi di sekolah tersebut sudah beragam. Proses pembelajaran selama ini sudah menerapkan model pembelajaran kooperatif dengan menggunakan kurikulum 2013 (K-13), kadang juga diselingi dengan metode ceramah maupun diskusi dengan membagi siswa dalam bentuk kelompok dan mengharuskan siswa belajar atau menyelesaikan tugas bersama. Namun, disayangkan kerap kali dalam kelompok hanya beberapa siswa yang aktif menyelesaikan tugas nya, sedangkan sebagian siswa lainnya hanya mengandalkan teman sekelompoknya untuk menyelesaikan tugas mereka. Untuk itu, guru hendaknya lebih banyak mencoba pembelajaran aktif yang memberikan rasa tanggung jawab kepada setiap siswa agar tidak saling mengandalkan dan terciptanya rasa ketergantungan positif antar sesama anggota kelompok.

Model pembelajaran kooperatif merupakan suatu model dimana peserta didik membentuk kelompok kecil untuk saling membantu dan bekerjasama dalam mempelajari suatu materi pelajaran (Azizah, et al., 2017). Huda (2013) mengatakan kelompok kooperatif sebagai suasana pembelajaran dimana siswa saling berinteraksi di dalam kelompok kecil untuk menyelesaikan permasalahan dalam pembelajaran dan mencapai tujuan bersama. Strategi pembelajaran kooperatif juga dapat meningkatkan kompetensi sosial peserta didik, kemampuan berkolaborasi, dan kemampuan interaksi antar peserta didik (Karacop dan Doymus, 2012). Menurut Lie (2002) pembelajaran kooperatif dapat mencapai hasil yang maksimal apabila menerapkan lima unsur pembelajaran kooperatif yaitu, saling ketergantungan positif, tanggung jawab perseorang, tatap muka, komunikasi antar anggota dan evaluasi proses kelompok. Salah satu model pembelajaran yang dapat digunakan yaitu Jigsaw II dan Think Pair Share (TPS).

Indrianie (2015) menyatakan bahwa model pembelajaran Jigsaw dirancang untuk meningkatkan rasa tangung jawab siswa terhadap pembelajarannya sendiri dan juga pembelajaran orang lain. Karena dalam model pembelajaran ini siswa tidak hanya mempelajari materi yang diberikan, tetapi mereka juga harus siap memberikan dan mengajarkan materi tersebut kepada anggota kelompoknya yang lain. Dengan demikian siswa saling tergantung dengan siswa yang lainnya dan harus bekerja sama secara kooperatif untuk mempelajari materi yang diberikan. Model pembelajaran kooperatif tipe TPS merupakan salah satu tipe pembelajaran kooperatif untuk memberi kesempatan kepada siswa untuk lebih banyak berfikir, menjawab dan saling membantu satu sama lain sehingga dapat mengemukakan jawaban yang sangat tepat, serta mendorong untuk meningkatkan kerja sama antar siswa (Mufidah, 2013).

Penerapan model pembelajaran tipe Jigaw II dan model TPS sama-sama dilakukan dalam bentuk kelompok, dimana siswa menjadi pusat kegiatan di kelas, sehingga di dalam kelompok siswa dapat berbagi ilmu pada teman sebaya dan memberikan kesempatan kepada siswa untuk tanya jawab kepada guru maupun siswa lainnya. Dari permasalahan diatas, maka tujuan penelitian ini adalah melihat perbedaan hasil belajar biologi siswa dengan menggunakan yaitu model pembelajaran tipe Jigsaw II dan model pembelajaran TPS pada kelas X IPA di SMA Negeri 18 Batam. 


\section{METODE PENELITIAN}

Jenis penelitian yang digunakan adalah penelitian quasi eksperimental. Dalam penelitian ini di ambil dua kelas yaitu: kelas eksperimen I $\left(\mathrm{X}_{1}\right)$ digunakan model pembelajaran kooperatif tipe Jigsaw II sedangkan kelas ekperimen II $\left(\mathrm{X}_{2}\right)$ menggunakan model pembelajaran TPS. Penelitian ini merupakan penelitian dengan hipotesis komparatif (perbandingan). Hal ini sesuai dengan pendapat Sugiyono (2013) hipotesis komparatif adalah pernyataan yang menunjukan dugaan nilai dalam satu variabel atau lebih pada sampel yang berbeda". Adapun desain eksperimen penelitian menurut Arikunto (2010) dapat dilihat pada Tabel 1.

Tabel 1. Desain Eksperimen Penelitian

\begin{tabular}{cccc}
\hline Kelas & Perlakuan & Posttes & Hasil Belajar \\
\hline Eksperimen 1 & $\mathrm{X}_{1}$ & $\mathrm{O}$ & $\mathrm{X}_{1} \mathrm{O}$ \\
Eksperimen 2 & $\mathrm{X}_{2}$ & $\mathrm{O}$ & $\mathrm{X}_{2} \mathrm{O}$ \\
\hline
\end{tabular}

Dimana, $\mathrm{X}_{1}=$ Perlakuan penelitian dengan menggunakan model Jigsaw II $; \mathrm{X}_{2}=$ Perlakuan penelitian dengan menggunakan model (TPS); $\mathrm{O}=$ Tes akhir (Posttest); $\mathrm{X}_{1} \mathrm{O}=$ hasil belajar dengan model Jigsaw II; $\mathrm{X}_{2} \mathrm{O}=$ hasil belajar dengan model TPS. Pada penelitian ini terdapat ada 2 (dua) variabel yang akan diukur, yaitu:

a. Variabel bebas adalah variabel yang mempengaruhi atau yang menjadi sebab perubahannya atau timbulnya variabel terikat $(\mathrm{X})$. Dalam penelitian ini variabel bebas yaitu kelas pembelajaran model Jigsaw II dan TPS.

b. Variabel terikat adalah variabel yang dipengaruhi atau menjadi akibat karena adanya variabel bebas. Variabel terikat dalam penelitian ini adalah hasil belajar (Y).

Sampel penelitian ditentukan dengan teknik Purposive Sampling yaitu kelas X IPA 2 dengan jumlah siswa sebanyak 32 siswa sebagai kelas eksperimen I, dan X IPA 1 sebanyak 32 siswa sebagai kelas eksperimen II. Teknik Purposive Sampling adalah teknik penentuan sampel dengan pertimbangan tertentu (Sugiyono, 2013). Pemilihan sampel berdasarkan kesamaan kemampuan siswa antara kelas eksperimen I dan eksperimen II yang dilihat dari data hasil belajar siswa yang relatif sama.

Data penelitian dianalisis dengan statistik deskriptif dan inferensial. Analisis statistik deskriptif digunakan untuk menyajikan data dalam distribusi frekuensi dan disajikan dalam bentuk tabel. Analisis statistik inferensial dilakukan untuk pengujian hipotesis. Sebelum melakukan pengujian hipotesis, terlebih dahulu dilakukan uji normalitas data dan uji homogenitas. Uji normalitas menggunakan chi kuadrat dan uji homogenitas menggunakan varians. Pengujian hipotesis dilakukan dengan menggunakan uji $\mathrm{t}$ pada taraf signifikan $\alpha=$ $0,05 \%$.

\section{HASIL DAN PEMBAHASAN}

Dari penelitian yang telah dilakukan pada kelas eksperimen I dan ekperimen II diperoleh data tentang hasil belajar. Data yang diperoleh dalam penelitian ini adalah hasil posttest atau data hasil belajar akhir pada kegiatan penelitian. Berdasarkan hasil analisis jawaban siswa pada kegiatan tes akhir diperoleh data nilai rata-rata hasil belajar siswa yang terlihat pada Tabel 2 . 
Tabel 2. Nilai Rata-rata, Simpangan Baku dan Varians kelas Eksperimen I dan Eksperimen II

\begin{tabular}{ccccc}
\hline KELAS & $\mathbf{n}$ & $\overline{\mathbf{X}}$ & $\mathbf{S}$ & $\mathbf{S}^{\mathbf{2}}$ \\
\hline Jigsaw II & 32 & 82,5 & 11,15 & 124,39 \\
TPS & 32 & 76,5 & 9,7 & 102,36 \\
\hline
\end{tabular}

Pada Tabel 2. dapat dilihat bahwa hasil belajar siswa pada kelas eksperimen I yang diberi perlakuan dengan model Jigsaw II memiliki nilai rata-rata yang lebih tinggi dari hasil belajar siswa pada kelas ekperimen II yang diberi perlakuan dengan model TPS. Nilai tertinggi denganpenerapan model Jigsaw II pada kelas eksperimen I adalah 97 dan nilai terendah 53. Uji normalitas pada data tersebut diperoleh nilai $X_{\text {hitung }}^{2} 5,346$ dan $\mathrm{dk} 6-3=3$ diperoleh $\mathrm{X}_{\text {tabel0,05 }}^{2}=$ 7,815 dengan demikian terlihat bahwa $X_{\text {hitung }}^{2}<X_{\text {tabel0,05 }}^{2}$ sehingga dapat ditarik kesimpulan bahwa sampel kelas eksperimen I berdistribusi normal.

Berdasarkan hasil belajar dengan penerapan model TPS pada kelas eksperimen II diperoleh nilai tertinggi 94 dan nilai terendah 50. Sehingga diperoleh nilai $X^{2}$ hitung $=1,56$ dan dk $6-3=3$ diperoleh $X_{\text {tabel0,05 }}^{2}=7,815$ dengan demikian terlihat bahwa $X_{\text {hitung }}^{2}<X_{\text {tabel0,05 }}^{2}$ sehingga dapat ditarik kesimpulan bahwa sampel kelas eksperimen II berdistribusi normal. untuk lebih jelasnya dapat dilihat pada Tabel 3.

Tabel 3. Hasil Uji Normalitas

\begin{tabular}{ccccc}
\hline Eksperimen & Sampel & $\mathbf{X}^{\mathbf{2}}$ & $\mathbf{X}_{\text {tabel 0.05 }}^{\mathbf{2}}$ & Kesimpulan \\
\hline Jigsaw II & 32 & 5,346 & 7,815 & Normal \\
Think Pair Share (TPS) & 32 & 1,56 & 7,815 & Normal \\
\hline
\end{tabular}

Untuk menentukan kelas eksperimen I dan eksperimen II apakah memiliki varians yang homogen atau tidak, maka dilakukan uji F. Sehingga, diperoleh $F_{\text {hitung }}=1,215$ dan $F_{\text {tabel0,05 }}$ 1,82. Karena $F_{\text {hitung }}<F_{\text {tabel }}$ maka dapat disimpulkan bahwa kedua kelompok data memiliki varians yang homogen. Berikut adalah hasil pengujian homogenitas dapat dilihat pada Tabel 4. Tabel 4. Hasil perhitungan Uji Homogenitas

\begin{tabular}{ccc}
\hline Keterangan & Jigsaw II & Think Pair Share (TPS) \\
\hline Standar Deviasi & 11,15 & 9,7 \\
Varians & 124,39 & 102,36 \\
\hline$F_{\text {hitung }}$ & & 1,215 \\
$F_{\text {tabel0.05 }}$ & 1,82 \\
$\mathrm{n}$ & 32 \\
\hline
\end{tabular}

Langkah selanjutnya adalah melakukan uji hipotesis, untuk mengetahui apakah terdapat perbedaan hasil belajar dengan menggunakan metode Jigsaw II dan TPS. Untuk melihat hasil uji hipotesis dapat dilihat pada Tabel 5.

Tabel 5. Hasil Uji Hipotesis

\begin{tabular}{cccc}
\hline Kelas & $\mathbf{t}_{\text {hitung }}$ & $\mathbf{t}_{\text {tabel }}$ & Kesimpulan \\
\hline $\begin{array}{c}\text { Jigsaw II } \\
\text { TPS }\end{array}$ & 2,26 & 1,99 & Hipotesis diterima \\
\hline
\end{tabular}

Dari hasil perhitungan dengan uji-t didapat harga $t_{\text {hitung }}$ 2,26 dan taraf nyata 0,05 didapat hrag $t_{\text {tabel }} 1,99$. Karena $t_{\text {hitung }}>t_{\text {tabel }}$, maka dapat dikatakan bahwa hipotsis diterima. Dapat 
disimpulkan bahwa terdapat perbedaan dari hasil belajar biologi siswa menggunakan model pembelajaran Jigsaw II dan model pembelajaran TPS pada pokok bahasan Ekosistem kelas X IPA SMA Negeri 18 Batam.

SMA Negeri 18 Batam memiliki Kriteria Ketuntasan Minimal (KKM) yaitu 70. Pada kelas Ekperimen I setelah dilakukan pembelajaran dengan menggunakan model pembelajaran kooperatif tipe Jigsaw II diperoleh hasil posttest yaitu siswa memperoleh ketuntasan belajar berjumlah 29 orang, sedangkan siswa yang tidak tuntas berjumlah 3 orang.

Pada kelas Ekperimen II setelah dilakukan pembelajaran dengan menggunakan model pembelajaran kooperatif tipe TPS diperoleh hasil posttest yaitu siswa memperoleh ketuntasan belajar berjumlah 27 orang, sedangkan siswa yang tidak tuntas berjumlah 5 orang siswa. Nilai ketuntasan pada kelas Eksperimen I dan Eksperimen II dapat dilihat pada Tabel 6.

Tabel 6. Nilai Ketuntasan Kelas Eksperimen I dan Ekperimen I

\begin{tabular}{ccccc}
\hline \multirow{2}{*}{$\begin{array}{c}\text { Kelas } \\
\text { Perlakuan }\end{array}$} & \multirow{2}{*}{ KKM } & \multirow{2}{*}{ Jumlah Siswa } & \multicolumn{2}{c}{ Nilai Post Test } \\
\cline { 4 - 5 } Eksperimen I & \multirow{2}{*}{70} & 32 & 29 & Tuntas \\
Eksperimen II & & 32 & 27 & 5 \\
\hline
\end{tabular}

Persentase nilai ketuntasan kelas eksperimen I dan kelas eksperimen II divisualisasikan pada Gambar 1. Pada kelas eksperimen I persentase siswa yang tuntas sebanyak $91 \%$ dan siswa yang tidak tuntas sebanyak 9\%, sedangkan pada kelas eksperimen II siswa yang tuntas sebanyak $84 \%$ dan siswa yang tidak tuntas sebanyak $16 \%$.

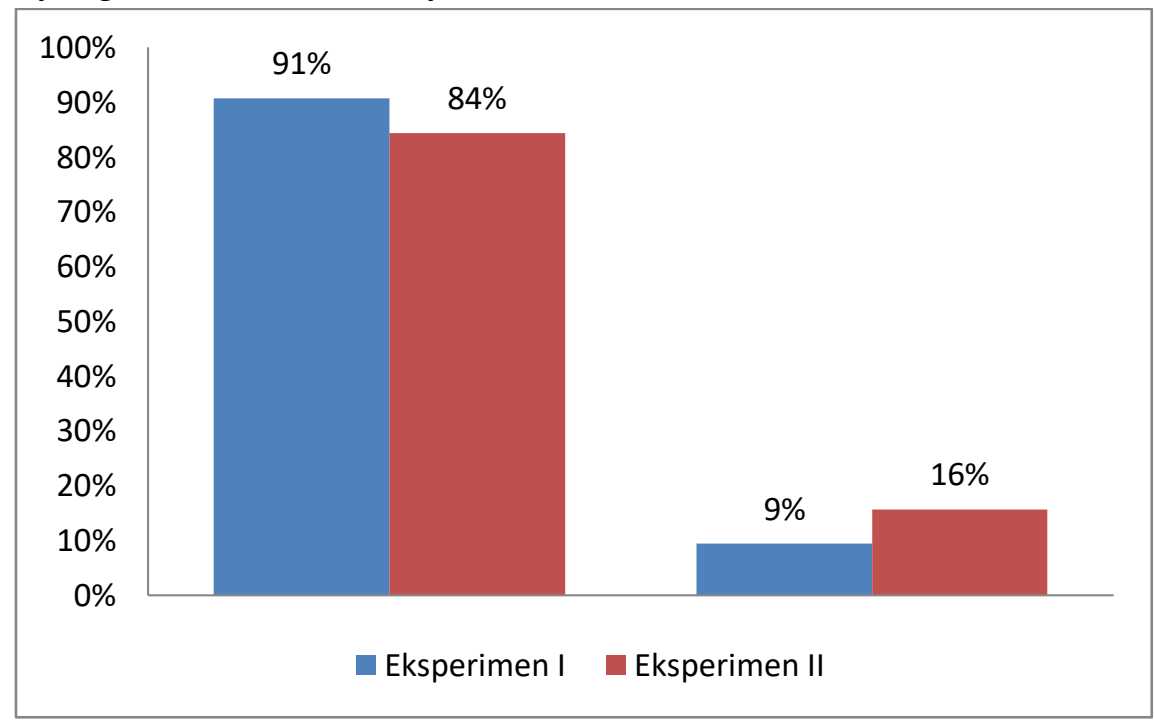

Gambar 1. Ketuntasan Hasil Belajar Siswa Kelas Ekperimen I dan Ekperimen II

Perbedaan hasil belajar siswa pada kelas ekperimen I dan II membuktikan bahwa perbedaan model pembelajaran yang diterapkan akan berpengaruh terhadap hasil belajar siswa. Dengan demikian, guru harus mampu menyampaikan materi dengan berbagai model pembelajaran agar pembelajaran dapat berlangsung dengan baik dan tidak monoton. Salah satu guru yang berkualitas adalah guru yang kreatif dalam menyampaikan materi dengan model dan strategi dalam pembelajaran. 
Dari hasil test yang diperoleh, masih terdapat beberapa siswa yang belum tuntas dalam proses pembelajaran. Hal ini disebabkan oleh beberapa faktor yang menjadi kendala selama penelitian berlangsung. Kendala tersebut ada yang berasal dari diri siswa, dimana siswa menganggap bahwa pelajaran biologi sulit dipahami sehingga ada beberapa siswa yang bermain disaat peneliti menerangkan pelajaran. Penerapan model yang berbeda pada dua kelas memberikan hasil akhir yang berbeda pula.

Hasil uji hipotesis penelitian ini menunjukan bahwa proses pembelajaran materi ekosistem dengan menerapkan model pembelajaran Jigsaw II dapat meningkatkan nilai rata-rata hasil belajar biologi siswa dibandingkan pembelajaran dengan model TPS. Hal ini sama dengan penelitian relevan yang dilakukan oleh Lestari (2014) mengemukakan bahwa model pembelajaran tipe Jigsaw II memberikan pengaruh yang lebih baik dan hasil lebih tinggi dari pada model pembelajaran TPS. Hal ini dikarenakan pembelajaran kooperatif tipe Jigsaw II merupakan salah satu tipe pembelajaran kooperatif yang mendorong siswa aktif dan saling membantu dalam menguasai materi pelajaran untuk mencapai prestasi yang maksimal (Sulastri dan Rochintaniawati, 2009).

Interaksi pada kelas eksperimen I terlihat lebih baik dari eksperimen II karena siswa diharuskan untuk berdiskusi dan bekerja sama tidak hanya dengan kelompok asal tetapi juga dengan sesama anggota kelompok ahli dengan materi yang sama. Didukung oleh Shoimin (2014) dalam model pembelajaran Jigsaw II, siswa memiliki banyak kesempatan untuk mengemukakan pendapat dan mengolah informasi yang didapat dan dapat meningkatkan keterampilan berkomunikasi. Penggunaan model TPS di kelas eksperimen II siswa sebagian besar menunjukan kurangnya antusias dalam belajar dan kurang berperan aktif dan masih menggantungkan pada pasangan dalam menemukan penyelesaian soal namun masih dalam konteks fokus pembelajaran. Hal yang sama juga dikemukakan Fadila et al., (2019) bahwa model TPS ini kurang efektif karena banyak kelompok yang perlu diawasi guru, ide yang dihasilkan siswa lebih sedikit karena hanya berpasangan, dan ide-ide nya bergantungnya siswa pada pasangannya masing-masing.

Perbedaan antara model pembelajaran Jigsaw II dan TPS yaitu pada saat pembentukan kelompok dan proses siswa dalam mendapatkan materi. Untuk model pembelajaran Jigsaw II pada saat pembentukan kelompok proses pembentukan kelompok guru (peneliti) yang menentukan kelompoknya, sehingga kelompok benar-benar heterogen karena siswa tidak dapat menentukan kelompoknya sendiri berdasarkan teman dekat, kecerdasan, dll. Selain itu pada model pembelajaran Jigsaw II siswa dikelompokkan dalam tim ahli dan tim asal. Sedangkan pada model pembelajaran TPS proses pembentukan kelompok ditentukan oleh posisi tempat duduk. Jadi kelompok sesuai dengan apa yang diinginkan siswa. Selain itu materi yang didapatkan tidak sepaham seperti model Jigsaw II karena siswa belajar berdasarkan pertanyaan yang diajukan oleh guru (peneliti) dan lebih sedikit ide yang muncul.

Peneliti menyadari dalam melaksanakan model Jigsaw II dan model TPS masih banyak terdapat kekurangan dan kelemahan. Tetapi penelitian yang sudah dilakukan sudah dapat dikatakan lebih baik dapat dilihat dari hasil belajar siswa yang meningkat. Guna meningkatkan hasil belajar biologi siswa dan memenuhi ketentuan belajar secara kelompok, yaitu peneliti harus dapat mengalokasikan waktu seefisien mungkin serta dapat mengelola kelas dengan baik. 


\section{KESIMPULAN}

Terdapat perbedaan hasil belajar biologi dengan menggunakan model Jigsaw II dan TPS pada siswa kelas X IPA SMAN 18 Batam. Pencapaian hasil belajar siswa eksperimen I yang diajarkan dengan menggunakan model Jigsaw II lebih tinggi dibandingkan dengan kelas eksperimen II yang diajarkan dengan model TPS, yaitu 82,5 berbanding 76,5.

\section{REFERENSI}

Arikunto, S. 2010. Dasar-Dasar Evaluasi Pendidikan. Bumi Aksara. Jakarta. 310 hal.

Azizah, Z., Wahyu, W., dan Yuliani, G. 2017. Pengaruh Model Pembelajaran Kooperatif Jigsaw Ii Terhadap Penguasaan Konsep Dan Kecemasan Sma Kelas Xi Pada Materi Sistem Koloid. Jurnal Ipteks Terapan: Research of Applied Science and Education, 11(1): 89-98.

Huda, M., 2013. Cooperative Learning. Pustaka Belajar, Yogyakarta. xxiv + 430 halaman.

Fadila, I.P., Imron A., dan Susanto, H. 2019. Perbandingan Hasil Belajar Siswa Yang Menggunakan Model Pembelajaran Think Talk Write dan Think Pair Share. Jurnal Pendidikan dan Penelitian Sejarah, 7 (7): 1-12.

Indrianie, N. S. 2015. Pengaruh Jigsaw dan Motivasi Belajar Pada Mapel Mata Pelajaran Bahasa Inggris "Reported Speech" Terhadap Hasil Belajar Siswa Kelas X SMA Taman Madya Kota Probolinggo. Jurnal Inovasi Pembelajaran, 1(2): 163-173

Karacop, A., and Doymus, K. 2012. Effects of Jigsaw Cooperative Learning and Animation Techniques on Students' Understanding of Chemical Bonding and Their Conceptions of the Particulate Nature of Matter. Journal of Science Education and Technology, 22(2): 186-203. http://doi.org/10.1007/s10956-012-9385-9

Lestari, A. D. 2014. Perbedaan Hasil Belajar IPA-Biologi Dengan Menggunakan Model Pembelajaran TPS (Think Pair Share) Dan Model Pembelajaran Jigsaw Siswa Kelas VIII SMP Negeri 2 Kartasura Tahun Pelajaran 2013/2014. (Skrips). Fakultas Keguruan Dan Ilmu Pendidikan. Universitas Muhammadiyah Surakarta. Surakarta.

Lie, A. 2002. Cooperatif Learning. Gramedia Widiasarana Indonesia, Jakarta. 96 hal.

Mufidah, L., 2013. Penerapan Model Pembelajaran Kooperatif Tipe Tps Untuk Meningkatkan Aktivitas Belajar Siswa Pada Pokok Bahasan Matriks. Jurnal Pendidikan Matematika STKIP PGRI. Sidoarjo, 1 (1): 117-125

Rinaldi, R. 2018. Pengaruh Penggunaan Model Pembelajaran Kooperatif Tipe Think Pair Share (TPS) terhadap Hasil belajar Biologi Siswa Pada Materi Pokok Sel di Kelas XI SMA Negeri 1 Batang Onang. Jurnal Education and development. 5(2): 24-27

Samaela, D. P., Jamhari, M., dan Kundera, I. N., 2017. Pengaruh Model Pembelajaran Kooperatif Tipe Jigsaw II dan Teknik Peta Pikiran terhadap Hasil Belajar Siswa Kelas X SMA Negeri 3 Poso pada Mata Pelajaran Biologi. e-Jurnal Mitra Sains, 5(2): 48-57.

Shoimin, A. 2014. 68 Model Pembelajaran Inovatif Dalam Kurikulum 2013. Ar-Ruzz Media, Yogyakarta. 239 hal.

Slameto. 2010. Belajar dan Faktor-Faktor yang Mempengaruhinya. Rineka Cipta. Jakarta. 195 hal. 
Sugiyono. 2013. Metode Penelitian Kuantitatif, Kulitatif dan R\&D. Alfabeta. Bandung. 464 hal.

Sulastri, Y., dan Rochintaniawati, D. 2009. Pengaruh Penggunaan Pembelajaran Kooperatif Tipe Jigsaw Dalam Pembelajaran Biologi di SMPN 2 Cimalaka. Jurnal Pengajaran MIPA, 13 (1): $15-21$.

\begin{abstract}
Authors:
Alnita Saputri, Program Studi Pendidikan Biologi Fakultas Keguruan dan Ilmu Pendidikan, Universitas Riau Kepulauan, Kampus Universitas Riau Kepulauan, Jl. Batu Aji Baru No. 99, (29433), Propinsi Kepulauan Riau , Indonesia email: alnitasaputri@gmail.com

Fauziah Syamsi, Program Studi Pendidikan Biologi Fakultas Keguruan dan Ilmu Pendidikan, Universitas Riau Kepulauan, Kampus Universitas Riau Kepulauan, Jl. Batu Aji Baru No. 99, (29433), Propinsi Kepulauan Riau, Indonesia email: fauziahsyamsi@gmail.com

Notowinarto, Program Studi Pendidikan Biologi Fakultas Keguruan dan Ilmu Pendidikan, Universitas Riau Kepulauan, Kampus Universitas Riau Kepulauan, Jl. Batu Aji Baru No. 99, (29433), Propinsi Kepulauan Riau, Indonesia, email: notowinarto@yahoo.co.id

This is an open-access article distributed under the terms of the Creative Commons Attribution License, which permits unrestricted use, distribution and reproduction in any medium, provided the original author and source are credited. (http://creativecommons.org/licenses/by/4.0/).
\end{abstract}

\title{
How to cite this article:
}

Saputri, A., Syamsi, F., and Notowinarto. 2020. Differences in biology learning outcomes using Jigsaw II and Think Pair Share (TPS) model on the subject of ecosystem at class X Natural Sciences SMA Negeri 18 Batam. Simbiosa, 9(1): 52-59. Doi. http://dx.doi.org/10.33373/sim-bio.v9i1.2474. 